\title{
Functional and radiological characteristics of asthma combined chronic obstructive pulmonary disease overlap
}

\author{
Hamada K. Fayed ${ }^{a}$, Yasen G. Abd-Elkareem ${ }^{a}$, Wassem A. Samaha ${ }^{b}$, \\ Maher S. Abdalshakour ${ }^{\mathrm{C}}$
}

\begin{abstract}
Background Persons with asthma-chronic obstructive pulmonary disease (COPD) overlap (ACO) are a crucial but poorly characterized group. In spite of the numbers of patients with ACO have increased, there is minimal confirmed evidence regarding diagnostic features and choices of treatment. So, the aim of this study was to identify the physiological and radiological characteristics of patients with ACO.
\end{abstract}

Patients and methods This study was performed on 200 patients classified into 38 patients diagnosed as having asthma, 132 patients diagnosed as having COPD, and 30 patients diagnosed as having $\mathrm{ACO}$, who were chosen based on clinical features. All patients underwent pulmonary function tests, and multislice computed tomography imaging.

Results The mean age of our study population was 61 years. The mean age in COPD group was higher compared with asthma and ACO groups $(63.9 \pm 7.8$ vs. $44.84 \pm 12.2$ and 56.7 \pm 8 , respectively), with a predominance of males in COPD and females in asthma, with a higher smoking index in patients with COPD than those with ACO and asthma (47.05 \pm 37.7 , $13.53 \pm 2.2$, and $2.47 \pm 1.46$, respectively). Measurements of forced expiratory volume in $1 \mathrm{~s}\left(\mathrm{FEV}_{1}\right)$ by liters before bronchodilator therapy is greater in patients with asthma than ACO and COPD groups $(1.89 \pm 0.42,1.52 \pm 0.39$, and 1.35 \pm 0.4 , respectively), with highly significant difference $(P<0.001)$. With airway reversibility, it is also greater in patients with asthma than ACO and COPD groups (2.85 $\pm 0.49,1.99 \pm 0.47$, and $1.41 \pm 0.39$, respectively), with a highly significant difference $(P<0.001)$. Airway internal diameter of patients with COPD is greater than ACO and asthma groups $(4.03 \pm 0.3,3.92 \pm 0.17$, and $2.82 \pm 0.31$, respectively), with a

\section{Introduction}

Asthma and chronic obstructive pulmonary disease have been identified as two separate diseases that usually overlap [1]. The Global Initiative for Asthma (GINA) and Chronic Obstructive Lung Disease (GOLD) have proposed a consensus document reaching to improve the characterization and description of these patients [2]. Individuals with asthma-chronic obstructive pulmonary disease overlap (ACO) are often identified as asthmatics with a history of smoking who show partial reversible airflow limitation or individuals with COPD who develop characteristics of asthma [3].

A joint project of GINA and GOLD provides a clinical identification of $\mathrm{ACO}$ as follows: $\mathrm{ACO}$ is characterized by persistent limitation of airflow with many criteria often associated with asthma and many criteria often associated with COPD. Therefore, ACO highly significant difference $(P<0.001)$. On the contrary, airway external diameter of patients with COPD is greater than asthma and ACO groups, with a highly significant difference $(P<0.001)$. Airway wall thickness of patients with asthma is greater than ACO and COPD groups, with a highly statistical difference $(P<0.001)$. There is no relation between thickness of airway wall and airway obstruction, expressed as $\mathrm{FEV}_{1}$ \%predicted, in patients with asthma and COPD. This study results confirmed the correlation between the thickness of airway wall and airway obstruction, expressed as FEV $1 \%$ predicted, in patients with ACO.

Conclusion Bronchial wall thickness measured by chest high resolution computed tomography (HRCT) is increased in patients with asthma than those with ACO and COPD, with a high statistical significance.

Egypt J Bronchol 2019 13:596-604

(C) 2020 Egyptian Journal of Bronchology

Egyptian Journal of Bronchology 2019 13:596-604

Keywords: asthma-chronic obstructive pulmonary disease overlap, asthma, chronic obstructive pulmonary disease

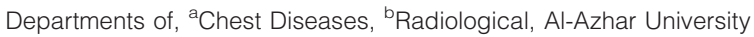
Hospital, ' Physiological Department, Al-Azhar University, Assiut, Egypt

Correspondence to Fayed H. Kawshty, MD, Chest Diseases Department, Al Forsan Building, Al-Azhar Street, Al-Azhar University Hospital, Assiut, Egypt. Tel: +20 109332 6825; fax: 0882149358; e-mail: kawshtey1978@yahoo.com

Received: 12 February 2019 Accepted: 6 May 2019 Published: 21 January 2020

is described by the criteria that it shares with both asthma and COPD [2]. As ACO has overlapping features of asthma and COPD, ACO may be a particular phenotype of a spectrum of chronic obstructive airway diseases, in which both asthma and COPD are at the two opposite ends. ACO is poorly characterized regarding genetic risk factors, underlying mechanisms, clinical criteria, pathological features, response to treatment, and outcome [4].

Patients with the overlap phenotype have more respiratory symptoms, worse lung function, and a lower health-related quality of life than either

This is an open access journal, and articles are distributed under the terms of the Creative Commons Attribution-NonCommercial-ShareAlike 4.0 License, which allows others to remix, tweak, and build upon the work non-commercially, as long as appropriate credit is given and the new creations are licensed under the identical terms. 
disease alone. Recently, the diagnostic features for the overlap phenotype have been confirmed by the consensus of a group of experts. However, this is restricted to patients with COPD but not for the asthma with fixed airflow obstruction [5].

The aim of our study is to analyze lung function tests and radiological characteristics of the overlap phenotype of asthma with COPD characteristic compared with agematched and sex-matched patients with only COPD and patients with only asthma.

\section{Patients and methods}

This prospective study was performed on 200 patients recruited randomly from chest department between May 2015 and May 2017. They were classified into 38 patients diagnosed as having asthma, 132 patients diagnosed as having COPD, and 30 patients diagnosed as having $\mathrm{ACO}$ according to diagnostic criteria.

The diagnosis of asthma, COPD, and ACO was dependent on GINA and GOLD [6]. Participants with asthma had reversible airflow obstruction with a post-bronchodilator forced expiratory volume in $1 \mathrm{~s}$ $\left(\mathrm{FEV}_{1}\right) /$ forced vital capacity $(\mathrm{FVC})$ at least $70 \%$ and post-bronchodilator $\mathrm{FEV}_{1}$ more than $80 \%$ of predicted. Individuals with COPD had incompletely reversible airflow obstruction with a postbronchodilator $\mathrm{FEV}_{1} / \mathrm{FVC}$ less than $70 \%$ and postbronchodilator $\mathrm{FEV}_{1}$ less than $80 \%$ of predicted.

The diagnosis of ACO was based on a joint statement reported by the GINA and the GOLD guidelines. Participants with ACO had respiratory symptoms, increased airflow variability [asthma, i.e. bronchial hyperresponsiveness (AHR) or Bronchodilator response $(\mathrm{BDR})]$, and incompletely reversible airflow obstruction (COPD): post-bronchodilator $\mathrm{FEV}_{1} / \mathrm{FVC}$ less than $70 \%$ and post-bronchodilator $\mathrm{FEV}_{1}$ less than $80 \%$ of predicted. ACO diagnosis was made when a patient had diagnostic features for both asthma and COPD [2].

Exclusion criteria were as follows: (a) any obvious abnormal pulmonary parenchymal lesions, including interstitial pneumonia; (b) pulmonary tumor; (c) congestive heart failure; (d) infectious disease including pulmonary tuberculosis; (e) other obstructive pulmonary illness such as diffuse panbronchiolitis; (f) cystic disease; (g) previous thoracotomy; (h) peripheral vascular disease; (i) thromboembolic disease (acute and chronic); (j) liver cell failure; and (k) any cognitive disorder.
The study was approved by the local ethical committee of our university, to evaluate and publish information. After explaining to the patients, a written consent was taken from all patients.

\section{Pulmonary functions test}

Pulmonary function testing was done for all patients according to American Thoracic Society criteria [7] using Medical Equipment Europe (Abteilung Entwicklung, Hammelburg, Germany). The largest $\mathrm{FEV}_{1}$ and $\mathrm{FVC}$ were recorded after examining all of the acceptable curves. $\mathrm{FEV}_{1}$ and $\mathrm{FVC}$ were measured in liters and percentage predicted before and after bronchodilator therapy. $\mathrm{FEV}_{1} / \mathrm{FVC} \%$ was measured by dividing actual $\mathrm{FEV}_{1}$ in liters over actual FVC in liters. American Thoracic Society criteria [7] require a rise in $\mathrm{FEV}_{1}$ of at least $200 \mathrm{ml}$ or $12 \%$ from baseline values, and a similar change in FVC of $200 \mathrm{ml}$ or $12 \%$, to indicate a response to a bronchodilator. Postbronchodilator $\mathrm{FEV}_{1} / \mathrm{FVC}$ less than 0.70 indicates irreversible airflow obstruction [6].

\section{Multislice computed tomography}

The multislice computed tomography (MSCT) of chest was done to evaluate MSCT features of asthma, COPD, and ACO and correlate these features with clinical and pulmonary function tests (spirometry).

MSCT was performed using 16-CT high-speed advantage scanner (Siemens, Erlangen) Somatom, made in Germany. Noncontrast high resolution computed tomography (HRCT) scanning was done at full inspiration with $1-\mathrm{mm}$ collimation at $120 \mathrm{kVp}$ (200 MAS) and matrix size of $512 \times 512$, and scans were taken at $10-\mathrm{mm}$ interval with window setting appropriate for the lungs (window level from 700 to $900 \mathrm{HU}$, width from 800 to1000 HU).

The lungs were scanned from the apex to the base with the patient lying in the supine position and holding his breath at full inspiration. Three reconstruction planes (axial, coronal, and sagittal) were automatically obtained.

The computed tomography (CT) images were enlarged (magnification, $\times 10$ ). Cross-sections of bronchi with external diameter range $1-5 \mathrm{~mm}$ were known and submitted for analysis. Only cross-sections perpendicular to the long airway axis were chosen. Regions of interest were traced manually. The external (D) and internal diameters of bronchi (L) were assessed by standard software analysis for distance measurement expressed in millimeters $(\mathrm{mm})$. All measurements were 
performed by a radiologist blinded to the patient's diagnosis. After $\mathrm{D}$ and $\mathrm{L}$ measurements, the following parameters were calculated: (a) WT, wall thickness, with the assumption that the bronchial wall thickness (BWT) is constant on the cross section [WT $=(\mathrm{D}-\mathrm{L}) / 2$ ], and $(\mathrm{b})$ BWT, outlined as the ratio of the wall thickness to the external diameter (BWT=WT/D) [8].

Scans were obtained at two selected levels: the trunk of the apical bronchus of the right upper lobe and the trunk of the posterior basal bronchus of the right lower lobe. We therefore decided to measure airway wall dimensions at only one of two sites in this study: the origin of the apical bronchus of the right upper lobe. This site was selected because of its more convenient orientation for obtaining a tangential view of the airway and an outer perimeter view of the airway not abutted by vessels or other bronchi.

\section{Statistical analysis}

Results are expressed as mean $\pm \mathrm{SD}$ for quantitative data and by number (\%) for qualitative data. Comparisons between the groups were conducted by independent sample $t$-test for parametric data and by Mann-Whitney test for nonparametric data. $\chi^{2}$-Test was used to test the significance between groups regarding qualitative data, and Fisher exact test was used instead of the $\chi^{2}$-test when the expected count in any cell found less than 5. $P$ value less than 0.05 was considered as significant. Data entry and all statistical analyses were performed using statistical package for the social sciences (SPSS) version 21 under Windows 7 operating system (SPSS Inc., Chicago, Illinois, USA).

\section{Results}

The general characteristics of patients are shown in Table 1. Male percentage was higher among COPD group compared with asthma and ACO groups (90.1 vs. 36.8 and $46.7 \%$, respectively). The female percentage was high among asthma compared with COPD and ACO groups (63.2 vs. 9.1 and 53.3\%, respectively), with a highly significant difference among these groups $(P<0.001)$. There is a highly significant difference regarding age among COPD group compared with asthma and ACO groups (63.9 vs. 44.84 and 56.7, respectively). The table also demonstrates no significant difference regarding BMI $(P>0.05)$, whereas the same table illustrates a highly significant difference regarding disease duration less than 0.001 . This table also clarifies high significant difference according to smoking index among COPD group compared with ACO and asthma groups (47.05 vs. 13.53 and 2.47 , respectively).

Measurements of $\mathrm{FEV}_{1}$ in liters before bronchodilator therapy is greater in asthma patients than $\mathrm{ACO}$ and COPD groups $(1.89 \pm 0.42,1.52 \pm 0.39$ and $1.35 \pm 0.39$, respectively), with a high significant difference $(P<0.001)$. With reversibility also it is greater in patients with asthma than ACO and COPD groups $(2.85 \pm 0.49,1.99 \pm 0.47$ and $1.41 \pm 0.4$, respectively), with a high significant difference $(P<0.001$; Table 2). Measurements of FVC in liters before bronchodilator therapy is greater in patients with asthma than $\mathrm{ACO}$ and COPD groups $(3.9 \pm 0.47,3.84 \pm 0.65$ and $3.43 \pm 0.63$, respectively), with a statistically significant difference $(P<0.049)$. Reversibility was also greater in patients with asthma than $\mathrm{ACO}$ and COPD groups $(4.08 \pm 0.38,3.87$ \pm 0.58 and $3.53 \pm 0.67$, respectively), with a high statistically significant difference $(P<0.001)$.

Airway internal diameter of patients with COPD is greater than $\mathrm{ACO}$ and asthma groups $(4.03 \pm 0.3,3.92$ \pm 0.17 and $2.82 \pm 0.31$, respectively), with a high statistically significant difference $(P<0.001)$. On the

Table 1 Comparison of baseline clinical characteristics of the studied groups

\begin{tabular}{|c|c|c|c|c|}
\hline Parameters & Asthma $(N=38)$ & COPD $(N=132)$ & $\operatorname{ACO}(N=30)$ & $P$ value \\
\hline Age (mean $\pm S D)$ (years) & $44.84 \pm 12.2$ & $63.9 \pm 7.8$ & $56.7 \pm 8$ & $<0.001^{* *}$ \\
\hline $\operatorname{Sex}[N(\%)]$ & & & & $<0.001^{* *}$ \\
\hline Males & $14(36.8)$ & $120(90.9)$ & $16(53.3)$ & \\
\hline Females & $24(63.2)$ & $12(9.1)$ & $14(46.7)$ & \\
\hline Disease duration (mean $\pm S D$ ) & $14.26 \pm 8.7$ & $11.24 \pm 6.6$ & $21.4 \pm 8.48$ & $<0.001^{\star *}$ \\
\hline BMI (mean $\pm S D)$ & $27.5 \pm 3.07$ & $26.68 \pm 3.03$ & $27.9 \pm 3.3$ & 0.56 \\
\hline Smoking history [N (\%)] & & & & 0.7 \\
\hline Never & $8(21.1)$ & $12(9.1)$ & $2(6.6)$ & \\
\hline Ex-smoker & $18(47.3)$ & $74(56.1)$ & $14(46.7)$ & \\
\hline Smoker & $12(31.6)$ & $46(34.8)$ & $14(46.7)$ & \\
\hline Smoking index (pack-year) (mean $\pm S D)$ & $2.47 \pm 1.46$ & $47.05 \pm 37.7$ & $13.53 \pm 2.2$ & $<0.001^{* *}$ \\
\hline
\end{tabular}

ACO, asthma-chronic obstructive pulmonary disease overlap; COPD, chronic obstructive pulmonary disease. ${ }^{* \star} P$ value is highly significant. 
Table 2 Comparison of pulmonary function parameters (before and after bronchodilator therapy) among asthma, chronic obstructive pulmonary disease and asthma-chronic obstructive pulmonary disease overlap groups

\begin{tabular}{|c|c|c|c|c|}
\hline & Pulmonary function tests & Before bronchodilator therapy $($ mean $\pm S D)$ & After bronchodilator therapy $(\operatorname{mean} \pm S D)$ & $P$ value \\
\hline \multirow[t]{5}{*}{ Asthma } & $\mathrm{FEV}_{1}(\mathrm{I})$ & $1.85 \pm 0.42$ & $2.85 \pm 0.49$ & $<0.045^{*}$ \\
\hline & \%Predicted & $64.26 \pm 16.63$ & $100.58 \pm 22.98$ & $<0.003^{*}$ \\
\hline & FVC (I) & $3.89 \pm 0.47$ & $4.09 \pm 0.38$ & 0.69 \\
\hline & $\%$ Predicted & $115.6 \pm 26.18$ & $120.8 \pm 24$ & 0.45 \\
\hline & $\mathrm{FEV}_{1} / \mathrm{FVC} \%$ & $47.84 \pm 8.39$ & $73.63 \pm 7.24$ & 0.31 \\
\hline \multirow[t]{5}{*}{ COPD } & $\mathrm{FEV}_{1}(\mathrm{I})$ & $1.35 \pm 0.4$ & $1.41 \pm 0.39$ & 0.062 \\
\hline & \%Predicted & $48.67 \pm 13.76$ & $48.68 \pm 13.08$ & 0.98 \\
\hline & FVC (I) & $3.34 \pm 0.63$ & $3.53 \pm 0.67$ & $<0.001^{\star *}$ \\
\hline & \%Predicted & $90.5 \pm 19.43$ & $96.9 \pm 21.66$ & $<0.001^{* *}$ \\
\hline & $\mathrm{FEV}_{1} / \mathrm{FVC}^{2}$ & $40.3 \pm 10.17$ & $41.09 \pm 8.93$ & 0.33 \\
\hline \multirow[t]{5}{*}{$\mathrm{ACO}$} & $\mathrm{FEV}_{1}(\mathrm{I})$ & $1.52 \pm 0.39$ & $1.99 \pm 0.47$ & $<0.001^{* *}$ \\
\hline & \%Predicted & $56.67 \pm 15.7$ & $73.9 \pm 18.27$ & $<0.001^{* *}$ \\
\hline & FVC (I) & $3.84 \pm 0.66$ & $3.87 \pm 0.58$ & $<0.001^{\star *}$ \\
\hline & \%Predicted & $40.07 \pm 9.35$ & $50.7 \pm 28.7$ & $<0.001^{\star *}$ \\
\hline & $\mathrm{FEV}_{1} / \mathrm{FVC} \%$ & $40.07 \pm 9.35$ & $51.8 \pm 11.98$ & $<0.001^{* *}$ \\
\hline
\end{tabular}

$\mathrm{ACO}$, asthma-chronic obstructive pulmonary disease overlap; COPD, chronic obstructive pulmonary disease; FEV $(\mathrm{I})$, forced expiratory volume 1 per litters; FVC (I), forced vital capacity per litters. ${ }^{*} P$ value is significant. ${ }^{*} P$ value is highly significant.

contrary, airway external diameter of patients with COPD is greater than asthma and ACO groups, with a high statistically significant difference $(P<0.001)$. Airway wall thickness of patients with asthma is greater than $\mathrm{ACO}$ and $\mathrm{COPD}$ groups, with a high statistically significant difference $(P<0.001)$.

There is a high statistical significance in the correlation of post-bronchodilator $\mathrm{FEV}_{1}$ with dimensions of airway assessed in HRCT among patients with $\mathrm{ACO}$, whereas there is no statistical significance in the correlation of post-bronchodilator $\mathrm{FEV}_{1}$ with dimensions of airway assessed in HRCT among patients with COPD and asthma (Figs 1-5 and Tables 3-5).

\section{Discussion}

ACO was recently recognized by the GINA and the GOLD guidelines, which outlined this condition as being characterized by persistent airflow limitation together with many features often associated with asthma or COPD. The relatively recent identification of this condition has resulted in multiple definitions of ACO being used [9].

The prevalence of ACO varies from 1.6 to $4.5 \%$ in several studies all over the world [10]. If only individuals with asthma or COPD are included, the prevalence of $\mathrm{ACO}$ among patients with $\mathrm{COPD}$ varies from 12.1 to $55.2 \%$ and among patients with asthma from 13.3 to $61.0 \%$ [11].

Patients with ACO experience additional severe symptoms than those with either asthma or COPD
Figure 1

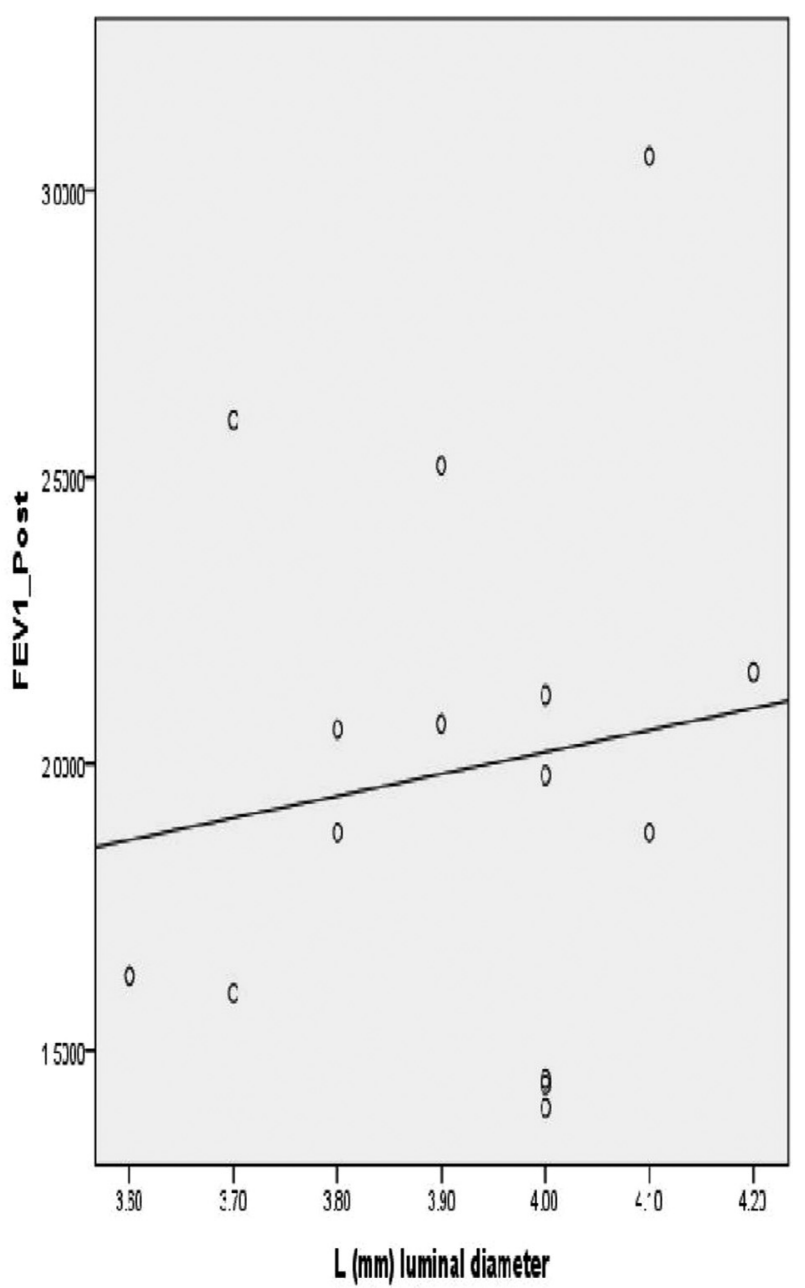

Correlation of a forced expiratory volume in $1 \mathrm{~s}$ after bronchodilator therapy with airway internal diameter assessed in HRCT among patients with asthma-chronic obstructive pulmonary disease overlap.

alone, with more frequent severe exacerbations and more frequent hospitalizations. Patients with ACO 
Figure 2

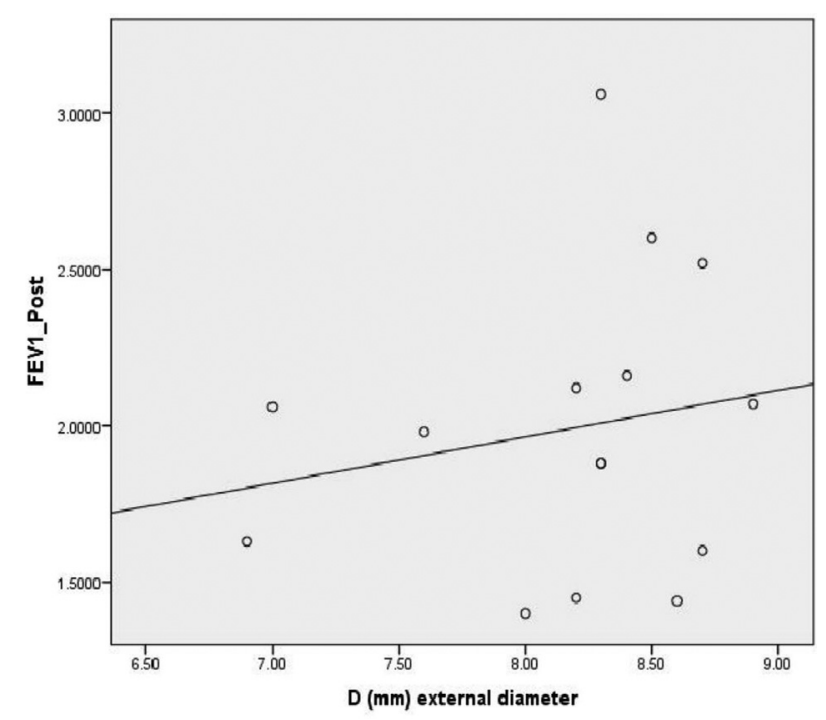

Correlation of a forced expiratory volume in $1 \mathrm{~s}$ after bronchodilator therapy with airway external diameter assessed in HRCT among patients with asthma-chronic obstructive pulmonary disease overlap.

\section{Figure 3}

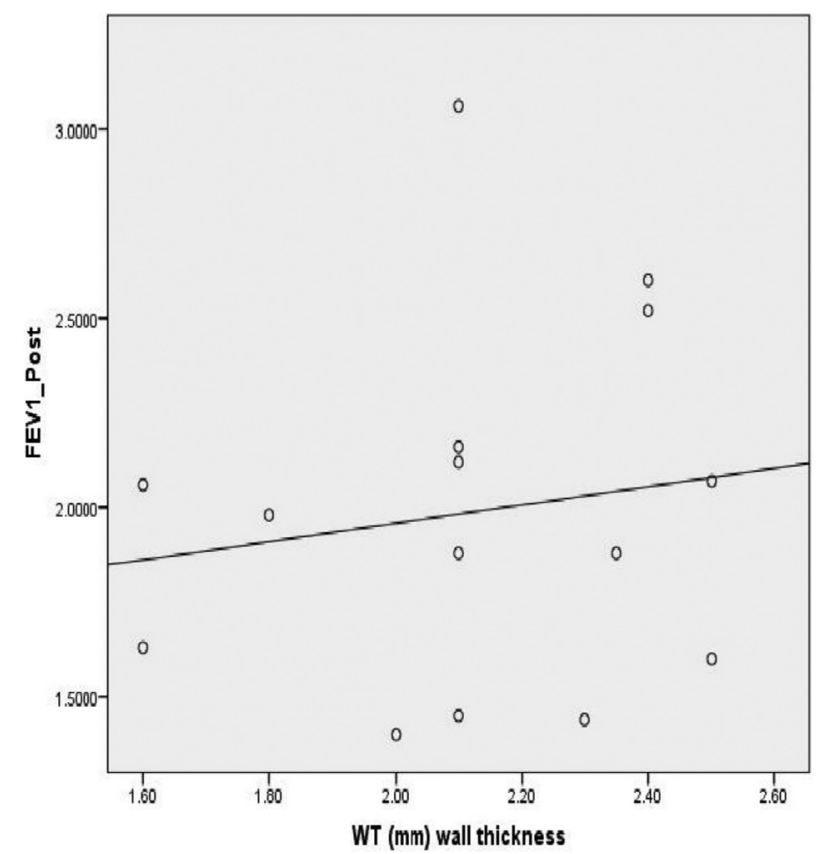

Correlation of a forced expiratory volume in $1 \mathrm{~s}$ after bronchodilator therapy with airway wall thickness assessed in HRCT among patients with asthma-chronic obstructive pulmonary disease overlap.

are significantly younger than those with COPD, with a higher BMI [12].

Regarding demographic data, the mean age of our study population is 61 years old, with high statistically significant difference among COPD compared with asthma and ACO groups (63.9 \pm 7.8 vs. $44.84 \pm 12.2$ and $56.7 \pm 8$, respectively). In agreement with our study, Ding and Small [13] and Gao et al. [14] found that COPD group is older than ACO and asthma. In contrast with our study, Kitaguchi et al. [15] found that the age has no statistical significant difference among COPD when compared with asthma and $\mathrm{ACO}$ groups $(71.9 \pm 0.8$ vs. $70.3 \pm 2.2$ and $69.1 \pm 1.2$, respectively).

Regarding sex, our study showed that males in ACO group were $53.3 \%$ and females were $46.7 \%$, whereas males in COPD group were $90.1 \%$ and females were $9.9 \%$, and males in asthma group were $36.8 \%$ and females were $63.2 \%$, with predominance of males in COPD group and females in asthma group. In agreement with this study, Montes et al. [16], Ding and Small [13], and Gao et al. [17] had nearly similar results. In contrast with this study, Menezes et al. [11] and Kumbhare et al. [18] founded that females were predominant in all groups, and this may be owing to large numbers of populations included in these studies.

The relative prevalence of $\mathrm{ACO}$ decreases with age, whereas that of COPD alone increases with age. This decline is owing to increase rate of growth of the COPD cohort more than that of ACO population or an increase in ACO death rates [19].

Regarding BMI, there is no significant statistical difference among the studied groups $(P>0.05)$. In agreement with this study, $\mathrm{Fu}$ et al. [20] and Mcdonald et al. [21], supported this study, with no significant statistical difference among the studied groups $(P>0.05)$. In contrast with this study, Ding and Small [13] and Kumbhare et al. [18] founded that ACO group has higher BMI than COPD and asthma groups, whereas Menezes et al. [11] founded that asthma group has higher BMI than ACO and COPD groups.

Regarding smoking index in our study, patients with COPD had higher smoking index than ACO and asthma groups $(47.05 \pm 37.7,13.53 \pm 2.2$, and 2.47 \pm 1.46 , respectively). This was consistent with Marco et al. [22], who found that patients with COPD had higher smoking index than ACO and asthma groups. In contrast to our study, Montes et al. [16] and Gao et al. [17] founded that smoking index is higher in $\mathrm{ACO}$ group than COPD and asthma groups.

In most studies, patients with asthma had a lower smoking index in comparison with COPD and ACO groups, and this may be explained by the younger age of asthmatic patients and cannot stand smoking. However, patients with asthma and COPD 


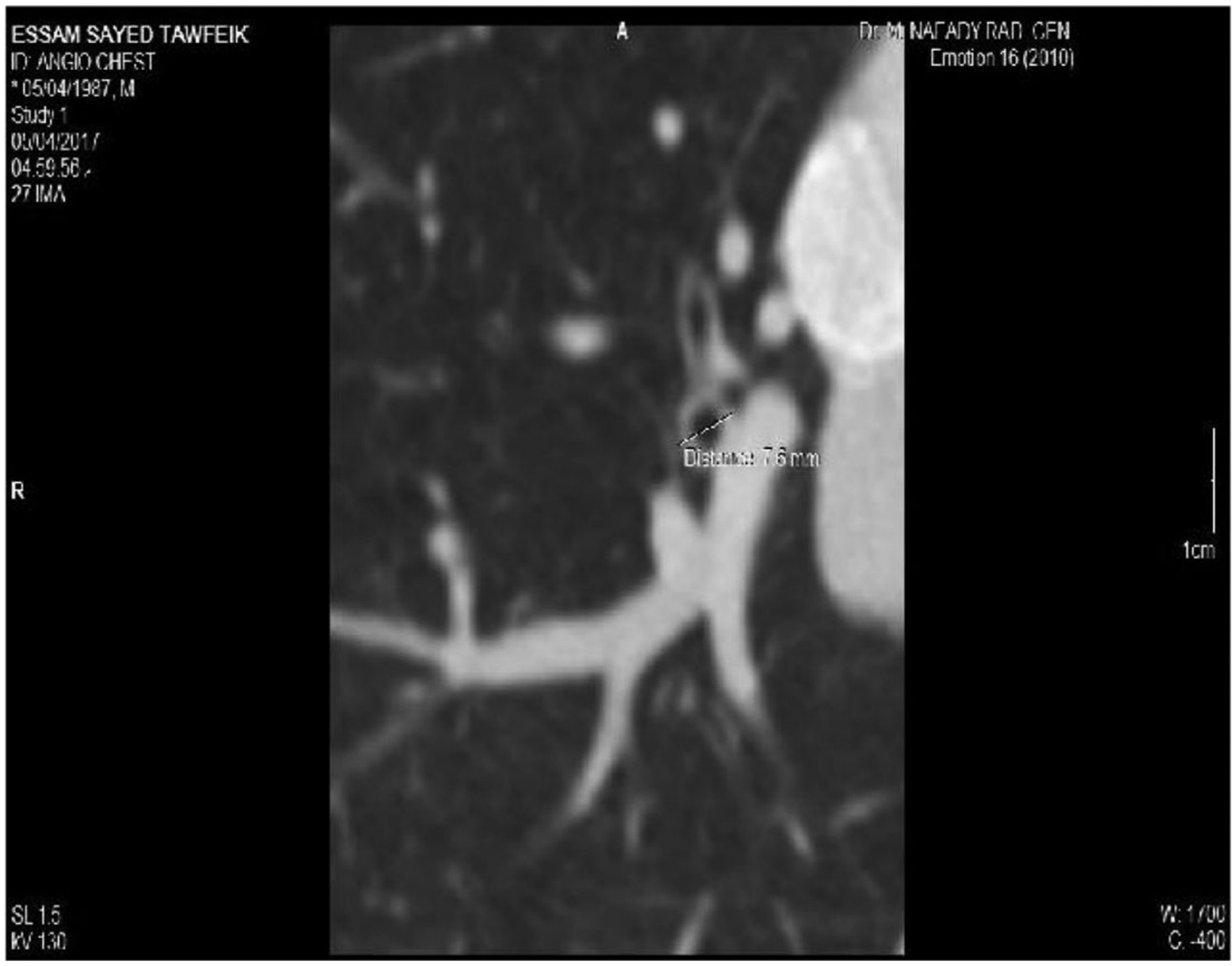

HRCT chest showing external diameter (D) of the apical bronchus of the right upper lobe measuring about $7.6 \mathrm{~mm}$.

who were ex-smokers are more than who currently smoke and never smoking, but in ACO, the smoker is similar to ex-smoker and both more than never smoking. This is supported by Maria Montes et al. [16] which found nearly the same results. In contrast to the current study, Chung et al. [23] found that asthma and ACO groups had more current smokers, but COPD group had more never smoking.

Spirometry is essential for the diagnosis and evaluation of obstructive pulmonary diseases that are characterized by decreased airflow related to increased resistance caused by narrowing of airway. This obstructions may occur either directly by the airway lumen narrowing or by reduced elasticity of the parenchyma surrounding the airways. $\mathrm{FEV}_{1}$ and $\mathrm{FEV}_{1} / \mathrm{FVC}$ values of the spirometric test are the best indicators for obstruction of airway [24].

Our study evaluated the differences in the pulmonary physiology in patients with obstructive pulmonary diseases and founded that there were significant differences in multiple parameters of pulmonary function tests among the COPD, asthma, and ACO groups. There were significant differences in the reversibility of airflow limitation in response to short-acting $\quad \beta 2$-agonists among patients with $\mathrm{COPD}, \mathrm{ACO}$, and asthma, and the reversibility of airflow limitation was the greatest in patients with asthma. In agreement with our study, Menezes et al. [11] supported that the reversibility of airflow limitation was the greatest in patients with asthma, whereas Kitaguchi et al. [15] founded that the reversibility of airflow limitation was the greatest in patients with ACO.

HRCT is a valuable tool in assessment of thickness of airway wall and dimension of airway lumen. It enables a noninvasive, reproducible evaluation of the airways at the bronchioles level. A relationship between basement membrane thickness assessed in biopsy specimens and airway wall thickness assessed by HRCT was documented. On the contrary, HRCT has its limitations. It enables the imaging of the total 


\section{Figure 5}

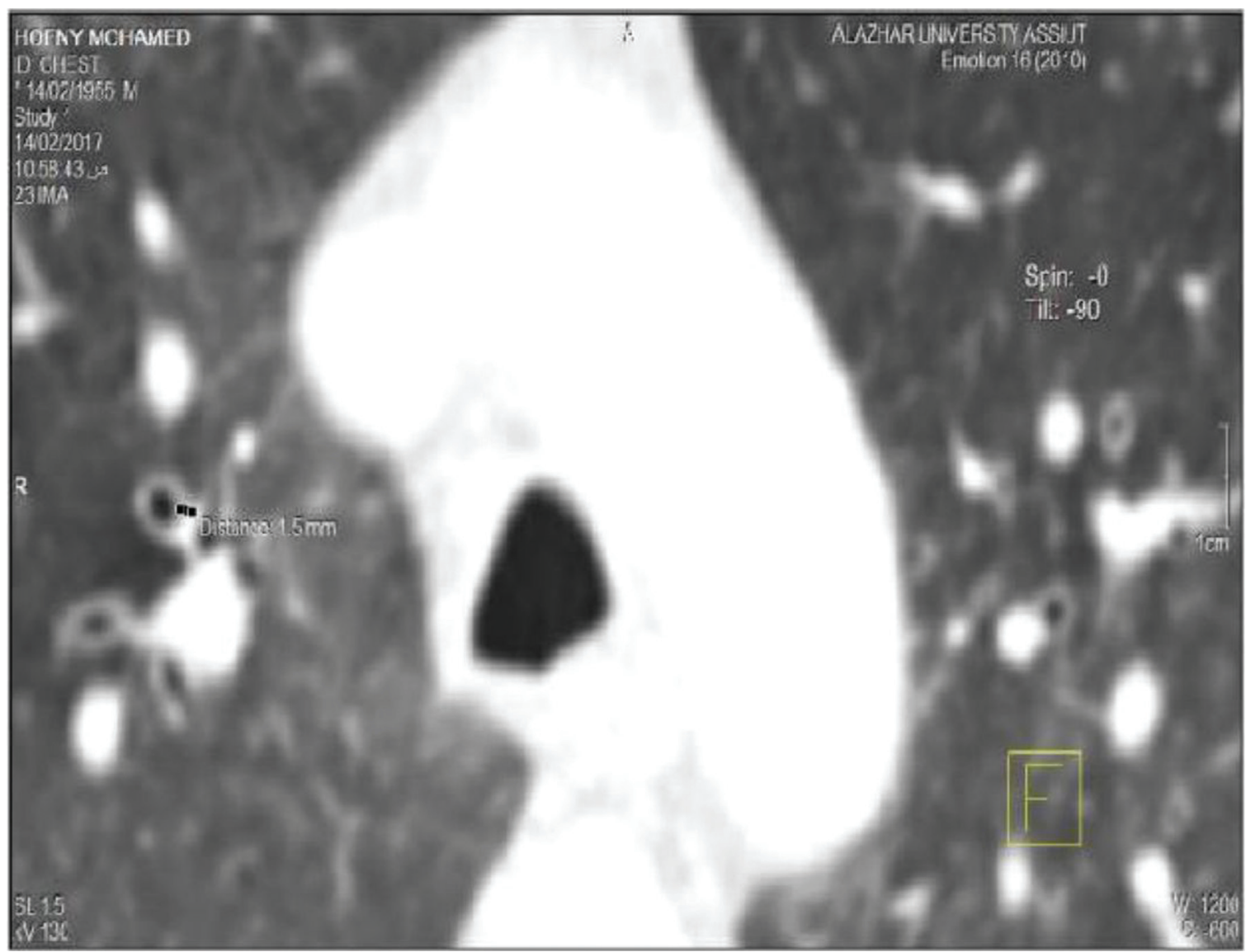

HRCT chest showing wall thickness (WT) of the apical bronchus of the right upper lobe measuring about $1.5 \mathrm{~mm}$.

Table 3 Comparison of forced expiratory volume in $1 \mathrm{~s}$ (\%predicted), forced vital capacity (\%predicted), and forced expiratory volume in $1 \mathrm{~s} /$ forced vital capacity\% after bronchodilator therapy among the studied groups

\begin{tabular}{lcccc}
\hline FEV $_{1}$, FVC and ratio (\%predicted) & Asthma $(N=38)$ & COPD $(N=132)$ & ACO $(N=30)$ & $P$ value \\
\hline FEV $_{1}$ (I) after bronchodilator therapy & $2.85 \pm 0.49$ & $1.41 \pm 0.39$ & $1.99 \pm 0.47$ & $<0.001^{* *}$ \\
$\%$ Predicted & $100.58 \pm 22.9$ & $48.68 \pm 13.08$ & $73.9 \pm 18.27$ & $<0.001^{* *}$ \\
FVC (I) after bronchodilator therapy & $4.08 \pm 0.38$ & $3.53 \pm 0.67$ & $3.87 \pm 0.58$ & $<0.001^{\star *}$ \\
\%Predicted & $120.8 \pm 24$ & $96.9 \pm 21.66$ & $50.7 \pm 28.8$ & $<0.001^{* *}$ \\
FEV $/$ FVC\% after bronchodilator therapy & $73.6 \pm 7.23$ & $41.09 \pm 8.3$ & $51.8 \pm 11.98$ & $<0.001^{* *}$ \\
\hline
\end{tabular}

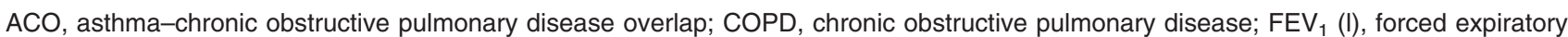
volume 1 in liters; FVC (I), forced vital capacity in liters. ${ }^{* \star} P$ value is statistically highly significant.

Table 4 Comparison of airway dimensions assessed in HRCT among the studied groups

\begin{tabular}{lcccc}
\hline Parameters & Asthma $(N=38)$ & COPD $(N=132)$ & ACO $(N=30)$ & $P$ value \\
\hline L $(\mathrm{mm})$ internal diameter & $2.82 \pm 0.31$ & $4.03 \pm 0.3$ & $3.92 \pm 0.17$ & $<0.001^{* *}$ \\
D $(\mathrm{mm})$ external diameter & $7.8 \pm 0.7$ & $8 \pm 0.36$ & $7.17 \pm 0.58$ & $<0.001^{* *}$ \\
WT $(\mathrm{mm})$ wall thickness & $2.78 \pm 0.38$ & $1.99 \pm 0.2$ & $2.1 \pm 0.34$ & $<0.001^{* *}$ \\
WT/D & $0.33 \pm 0.02$ & $0.24 \pm 0.17$ & $0.25 \pm 0.0 .04$ & $<0.001^{* *}$ \\
HRCT emphysema score & $2.5 \pm 0.5$ & $3.6 \pm 0.7$ & $0.6 \pm 0.3$ & $<0.035^{*}$ \\
\hline
\end{tabular}

ACO, asthma-chronic obstructive pulmonary disease overlap; COPD, chronic obstructive pulmonary disease; $D$ L, bronchial external diameter in millimeters; HRCT, high resolution computed tomography; $L$, bronchial internal diameter in millimeters; WT, wall thickness. ${ }^{*} P$ value is significant. ${ }^{* \star} P$ value is highly significant.

enlargement of the wall area or lumen area, but it does not provide with any information about each layer of the bronchial wall. Exposure of a patient to higher doses of radiation, compared with conventional chest radiograph, is still an important limitation of the method [25]. 
Table 5 Correlation of a forced expiratory volume in $1 \mathrm{~s}$ after bronchodilator therapy with airway dimensions assessed in HRCT among asthma, chronic obstructive pulmonary disease and asthma-chronic obstructive pulmonary disease overlap patients

\begin{tabular}{|c|c|c|c|}
\hline & Parameters & $\begin{array}{c}r \\
\text { value }\end{array}$ & $P$ value \\
\hline \multirow[t]{4}{*}{$\begin{array}{l}\text { Asthma } \mathrm{FEV}_{1} \text { after } \\
\text { bronchodilator therapy }\end{array}$} & $\begin{array}{l}\mathrm{L}(\mathrm{mm}) \text { luminal } \\
\text { diameter }\end{array}$ & -0.09 & 0.098 \\
\hline & $\begin{array}{l}\text { D }(\mathrm{mm}) \text { external } \\
\text { diameter }\end{array}$ & 0.012 & 0.96 \\
\hline & $\begin{array}{l}\text { WT }(\mathrm{mm}) \text { wall } \\
\text { thickness }\end{array}$ & 0.051 & 0.84 \\
\hline & WT/D & 0.31 & 0.18 \\
\hline \multirow[t]{4}{*}{$\begin{array}{l}\mathrm{COPD} \mathrm{FEV}_{1} \text { after } \\
\text { bronchodilator therapy }\end{array}$} & $\begin{array}{l}\mathrm{L}(\mathrm{mm}) \text { luminal } \\
\text { diameter }\end{array}$ & 0.093 & 0.45 \\
\hline & $\begin{array}{l}\mathrm{D}(\mathrm{mm}) \text { external } \\
\text { diameter }\end{array}$ & -0.19 & 0.12 \\
\hline & $\begin{array}{l}\text { WT }(\mathrm{mm}) \text { wall } \\
\text { thickness }\end{array}$ & -0.2 & 0.1 \\
\hline & WT/D & -0.19 & 0.12 \\
\hline \multirow[t]{4}{*}{$\begin{array}{l}\text { ACOS FEV }_{1} \text { after } \\
\text { bronchodilator therapy }\end{array}$} & $\begin{array}{l}\mathrm{L}(\mathrm{mm}) \text { luminal } \\
\text { diameter }\end{array}$ & 0.33 & $0.026^{*}$ \\
\hline & $\begin{array}{l}\mathrm{D}(\mathrm{mm}) \text { external } \\
\text { diameter }\end{array}$ & 0.6 & $<0.001^{\star \star}$ \\
\hline & $\begin{array}{l}\text { WT }(\mathrm{mm}) \text { wall } \\
\text { thickness }\end{array}$ & 0.51 & $<0.001^{* *}$ \\
\hline & WT/D & 0.41 & $<0.001^{\star \star}$ \\
\hline
\end{tabular}

ACO, asthma-chronic obstructive pulmonary disease overlap; COPD, chronic obstructive pulmonary disease; $\mathrm{D} L$, bronchial external diameter in millimeters; $F E V_{1}$, forced expiratory volume in $1 \mathrm{~s}$; HRCT, high resolution computed tomography; L, bronchial internal diameter in millimeters; WT, wall thickness. ${ }^{*} P$ value is significant. ${ }^{* *} P$ value is highly significant.

The greater thickness of airway wall in asthma can be partially explained by histological findings. The basement membrane thickness, smooth muscle layer, and the number of blood vessels in patients with asthma are greater than those in patients with COPD and ACO. Therefore, it is likely that airway remodeling results in a greater thickening of the airway wall in asthma when compared with COPD and ACO [26]. We did not find any relation between thickness of airway wall and airway obstruction, expressed as $\mathrm{FEV}_{1}$ $\%$ predicted, in asthmatic patients. On the contrary, the results of some other studies suggest that there is a correlation between airway wall thickening and disease severity [27].This study results confirm the correlation between the thickness of airway wall and airway obstruction, expressed as $\mathrm{FEV}_{1}$ \%predicted, in patients with ACO.

It should be noted, however, that airway wall remodeling is only one of the factors contributing to airflow limitation in asthma. Mucous membrane edema, inflammatory cell infiltration, increased mucus secretion, and smooth muscle constriction may influence airflow limitation. On the contrary, many genetic and environmental factors can influence spirometric results and airflow limitation [28].

In this study, there is no relationship between thickening of airway wall and spirometric parameters in patients with COPD. The bronchial wall thickness measured by chest HRCT is increased in patients with asthma than those with $\mathrm{ACO}$ and COPD, with a high statistically significant difference. However, the percentage of BWT on chest HRCT was lower in patients with ACO than those with asthma. Kitaguchi et al. [15] supported these findings in their study. This study suggests that patients with $\mathrm{ACO}$ have a lower degree of airway remodeling owing to asthma than patients with asthma. This variable pattern of remodeling may reflect primary differences in the inflammatory processes in asthma and COPD and could affect the reversibility of airflow limitation [15].

Our study had several limitations. One of them was a relatively small number of patients with $\mathrm{ACO}$ and patients with asthma. However, our data were accurate and reproducible, because all parameters were assessed using the same equipment. Another limitation was the lack of a second radiologist evaluating the airway. Lastly, there were different definitions used for the diagnosis of ACO. A confirmation study with a larger sample size of patients with ACO who are selected based on clinical criteria is warranted.

\section{Conclusion}

Obstructive airway diseases could be classified depending on clinical, radiological, and pulmonary function test findings into three groups including COPD, asthma, and ACO. Chest HRCT has a valuable tool in evaluating dimensions of small airway in patients with asthma, ACO and COPD. Lack of correlations between spirometric parameters and airway dimensions assessed in HRCT indicates that thickness of airway wall and lumen diameter are not the only factors that affect airflow limitation during forced expiration.

\section{Acknowledgements}

Fayed H. Kawshty and Galal Y. Abd-ElKareem participated in the performing the study. Fayed H. Kawshty conceived of the study and participated in its design and coordination and helped to draft the manuscript. Aldiasty W. Samaha carried out radiological analysis. Shabaan M. Abdalshakour performed the statistical analysis. All authors read and approved the final manuscript. 


\section{Financial support and sponsorship Nil.}

\section{Conflicts of interest}

There are no conflicts of interest.

\section{References}

1 Tam A, Sin DD. Pathobiologic mechanisms of chronic obstructive pulmonary disease. Med Clin North Am 2012; 96:681-698.

2 Global Initiative for Asthma, Global Initiative for Chronic Obstructive Lung Disease (GOLD). Asthma, COPD, and asthma-COPD overlap; 2017. Available at: www.ginasthma.org. [Accessed April 2017].

3 Sin DD, Miravitlles M, Mannino DM, Soriano JB, Price D, Celli BR, et al. What is asthma-COPD overlap syndrome? Towards a consensus definition from a round table discussion. Eur Respir J 2016; 48:664-673.

4 Postma DS, Reddel HK, Hacken NH, vanden BM. Asthma and chronic obstructive pulmonary disease: similarities and differences. Clin Chest Med 2014; 35:143-156.

5 Hardin M, Silverman EK, Barr RG, Hansel NN, Schroeder JD, Make BJ, et al. The clinical features of the overlap between COPD and asthma. Respir Res 2011; 12:127.

6 Global Initiative for Chronic Obstructive Lung Disease (GOLD). Global strategy for the diagnosis, management, and prevention of COPD. Available at: http://www.goldcopd.org. [Accessed 13 April 2018].

7 American Thoracic Society/European Respiratory Society. Standards for the diagnosis and management of patients with COPD. Eur Respir J 2004; 23:932-946.

8 Okazawa M, Muller N, McNamara AE, Child S, Verburgt L, Pare PD. Human airway narrowing measured using high resolution computed tomography. Am J Respir Crit Care Med 1996; 154:1557-1562.

9 Global Initiative for Asthma [webpage on the Internet]. Global strategy for asthma management and prevention. Available at: http://ginasthma.org/ 2017-pocket-guide-for-asthma-management-and-prevention/. [Accessed 19 January 2017].

10 Wurst KE, Kelly-Reif K, Bushnell GA, Pascoe S, Barnes N. Understanding asthma chronic obstructive pulmonary disease overlap syndrome. Respir Med 2016; 110:1-11.

11 Menezes AMB, Montes de Oca M, Perez-Padilla R, Nadeau G, Wehrmeister FC, Lopez-Varela MV, et al. Increased risk of exacerbation and hospitalization in subjects with an overlap phenotype: COPD-asthma. Chest 2014; 145:297-304.

12 Ding B, DiBonaventura M, Karlsson N, Ling X. Asthma-chronic obstructive pulmonary disease overlap syndrome in the urban Chinese population: prevalence and disease burden using the2010, 2012, and 2013 China National Health and Wellness surveys. Int $J$ Chron Obstruct Pulmon Dis 2016; 11:1139-1150.

13 Ding B, Small M. Treatment trends in patients with asthma-COPD overlap syndrome in a COPD cohort: findings from a real world survey. Int $J$ Chron Obstruct Pulmon Dis 2017; 12:1753-1763.
14 Gao J, Zhou W, Chen B, Lin W, Wu S, Wu F. Sputum cell count: biomarkers in the differentiation of asthma, COPD and asthma-COPD overlap. Int $J$ Chron Obstruct Pulmon Dis 2017; 12:2703-2710.

15 Kitaguchi Y, Yasuo M, Hanaoka M. Comparison of pulmonary function in patients with COPD, asthma-COPD overlap syndrome, and asthma with airflow limitation. Int J Chron Obstruct Pulmon Dis 2016; 11:991-997.

16 Montes de Oca M, Lopez Varela MV, Laucho-Contreras ME, Casas A, Schiavi E, Mora JC. Asthma-COPD overlap syndrome (ACOS) in primary care of four Latin America countries: the PUMA study. BMC Pulm Med 2017; 17:69.

17 Gao J, Iwamoto $\mathrm{H}$, Koskela J, Alenius $\mathrm{H}$, Hattori $\mathrm{N}$, Kohno $\mathrm{N}$, et al. Characterization of sputum biomarkers for asthma-COPD overlap syndrome. Int J Chron Obstruct Pulmon Dis 2016; 11:2457-2465.

18 Kumbhare S, Pleasants R, Ohar JA, Strange C. Characteristics and prevalence of asthma/chronic obstructive pulmonary disease overlap in the United States. Ann Am Thorac Soc 2016; 13:803-810.

19 Soriano JB, Visick GT, Muellerova H, Payvandi N, Hansell AL. Patterns of comorbidities in newly diagnosed COPD and asthma in primary care. Chest 2005; 128:2099-2107.

20 Fu J, McDonald VM, Gibson PG, Simpson JL. Systemic inflammation in older adults with asthma-COPD overlap syndrome. Allergy Asthma Immunol Res 2014; 6:316-324.

21 Mcdonald VM, Simpson JL, Higgins I, Gibson PG. Multidimensional assessment of older people with asthma and COPD: clinical management and health status. Age Ageing 2011; 40:42-49.

22 Marco R, Marcon A, Rossi A, Anto JM, Cerveri I, Gislason T, et al. Asthma, COPD and overlap syndrome: a longitudinal study in young European adults. Eur Respir J 2015; 46:671-679.

23 Chung JW, Kong KA, Lee JH, Lee SJ, Ryu YJ, Chang JH. Characteristics and self-rated health of overlap syndrome. Int $J$ Chron Obstruct Pulmon Dis 2014; 9:795-804.

24 Ozkaya S, Dirican A, Tuna T. The objective evaluation of obstructive pulmonary diseases with spirometry. Int $J$ Chron Obstruct Pulmon Dis 2016; 11:2009-2015.

25 Kosciuchi J, Krenk R, Gorska K, Zukowsk M, Maskey-Warzechowsk M, Chazan R. Relationship between airway wall thicknesses assessed by high resolution computed tomography and lung function in patients with asthma and chronic obstructive pulmonary disease. J Physiol Pharmacol 2009; 60:71-76.

26 Tanaka H, Yamada G, Saikai T, Hashimoto M, Tanaka S, Suzuki K, et al. Increased airway vascularity in newly diagnosed asthma using a high magnification bronchovideoscope. Am J Respir Crit Care Med 2003; 168:1495-1499.

27 Niimi A, Matsumoto $\mathrm{H}$, Amitani $\mathrm{R}$, Nakano $\mathrm{Y}$, Mishima M, Minakuchi $\mathrm{M}$, et al. Airway wall thickness in asthma assessed by computed tomography in relation to clinical indices. Am J Respir Crit Care Med 2000; 162:1518-1523.

28 Nosal S, Durdik P, Sutovska M, Franova S, Nosal V, Koppl J, et al. Changes of airway obstruction parameters in healthy children caused by mother's smoking during pregnancy. J Physiol Pharmacol 2008; 59:523-529. 